\title{
Research on the Training Mode of "the Three Functions are Integrated into one" Innovative Talents in Teaching-Research Universities
}

\author{
Fengjuan Wang ${ }^{1 a^{*}}$, Youzheng Cui ${ }^{2 b}$, Xingguo Wang ${ }^{3 c}$, Shufeng Jiang ${ }^{4 d}$ \\ ${ }^{1,2,3,4}$ Qiqihar University, No.42 Wenhua Ave, Qiqihar Jianhua district, Heilongjiang \\ a*657678158@qq.com; ${ }^{*} 634123048 @ q q . c o m,{ }^{c}$ 995687779@qq.com; ${ }^{\text {d } 474118867 @ q q . c o m}$
}

Keywords: Teaching reform; Innovative practice activities; Academic contest; Cultivation of innovative talents

\begin{abstract}
Training all-round practical, innovative and compound talents that fulfil the needs of the society is the emphasis of educational reform for teaching and research type colleges and universities. The cultivation of innovative talents is a powerful support for building an innovative country and innovation ability of college students is related to many factors, such as teaching reform, innovation and practice, and academic contest. This paper mainly analyzes the main elements of the "three in one" training mode and gives effective improvement measures. The analysis shows that the innovative consciousness of the students, the reform of curriculum teaching, the input of teachers' energy and the degree of discipline are the important factors that affect the "Trinity" training mode of innovative talents.
\end{abstract}

\section{Introduction}

Teaching and research universities are the backbone of China's higher education and undertaking the mission of training applied and innovative talents for the state and local economy and society, leading the development with theoretical application and technological innovation service[1]. The cultivation and improvement of College Students' innovative ability is the need of the times, the strategic need of building the country and the people, and the core of the current higher education reform. In recent years, colleges and universities are exploring the most effective mode for the cultivation of innovative talents.

\section{The main problems existing in the personnel training mode of teaching and research universities.}

The talents of teaching and research universities are trained with broad knowledge, strong adaptability to changes, excellent comprehensive quality, a certain combination of knowledge and innovative spirit, with pioneering spirit and research potential. Teaching and research universities are based on educating people, starting from the needs of students' development, paying attention to the main position of students, in line with all students, for the purpose of all students, adhering to the value of teachers in running a school, respecting teachers' value, giving full play to the spirit of the teachers and promoting the initiative and initiative of teachers and students. Creativity, inspire them to continue to explore the truth and the spirit of innovation, teaching and research universities are working hard to create academic research atmosphere and research soil, encourage innovation, and undertake academic responsibility for social services while adhering to academic freedom. However, teaching research universities still have the following problems in the cultivation of innovative talents:

Teaching means is single and teaching reform is imminent. Single teaching means is an important factor restricting the effectiveness of college students' innovative ability training[2]. At present, the disadvantages of teaching methods are common in Chinese universities. Teaching methods are mostly instillation, and should be transformed into applied two-way teaching methods. According to the nature of the curriculum, the diversified teaching methods, such as problem type, heuristic, seminar, discussion group, double division, case teaching and activity teaching, are used to change the teaching methods of a single class teaching and overcome the traditional "spoon-fed" 
teaching methods. In order to effectively improve the innovation ability of college students, it is necessary to reform the course teaching, change the malpractice of arousing the students' difficulty in learning enthusiasm, change the embarrassing situation of the teacher singing "one corner opera" in the classroom, change the students' passive learning as the active learning, and cultivate the students' interest and innovation ability through the inspiration and guidance.

Insufficient investment in the cultivation of college students' innovative ability. The innovation ability of university teachers and their investment in innovation are directly related to the effectiveness of college students' innovative ability. The cultivation of college students' sense of innovation and innovation ability depend largely on the guidance of university teachers and their own qualities. At present, the teaching task of teachers is heavy in many colleges and universities. The training of students' creative ability has not been paid or included in the system of evaluation, so that some teachers do not want to spend too much energy on improving students' creative ability.

Cultivating creative talents requires good material support. For example, it is necessary for the teachers to provide the teachers at home and abroad and to participate in academic exchanges, to increase the library related books and materials, to improve the teaching and experimental equipment and to strengthen the practical teaching of innovation and comprehensive practice. The needs of the development of the situation have appeared in many colleges and universities, the books and materials are aging or even lack, the teaching experimental equipment is obsolete, the teachers are difficult to learn and the practice teaching also exists in name only[3]. Many colleges and universities have no fixed teachers to guide college students' extracurricular scientific research activities. Even if some scientific and technological activities have guidance teachers, teachers should complete their own teaching and scientific research tasks, and it is difficult to separate the corresponding energy to guide the practical work of the students.

\section{Connotation of "Trinity" training mode in teaching and Research Universities}

The "three" in the training mode of "three in one" for innovative talents refer to the teaching reform, innovation practice and academic discipline competition of university theoretical courses. The teaching is the basic platform for students to study the basic theory and research methods. It is the basis for cultivating innovative talents. It is the basis for the cultivation of innovative talents. Reform the teaching methods, change the traditional teaching methods according to the characteristics of the courses, and adapt to the needs of students' interest in learning. It is a powerful support to train students' innovative ability to work out innovative and practical activities that are suitable for students' abilities. Let its innovative achievements take part in various innovative competitions between universities and stimulate students' enthusiasm for creation. The "one" means that the curriculum after the curriculum reform is more conducive to the students' interest in learning and to impart the students' theoretical knowledge. It is the necessary condition for cultivating the students' initiative and creativity. The holding of innovative practice activities is an important guarantee for cultivating students' practical ability and creative ability. Participating in the competition with the students' innovative results can motivate the students to make creative creative work. The three parties are integrated into one in order to cultivate innovative talents.

"Teaching reform, innovation and practice, academic contest", "Three in one", training mode is based on the reform of the theoretical curriculum, taking the innovation activities as the intermediary and taking the discipline competition as the form to guide and encourage the cultivation of students' innovative consciousness.

The curriculum reform is better imparted to the theoretical basis for the students and provides theoretical support for the discipline competition. The holding of the discipline competition is effectively mapped out of the insufficiency of the curriculum reform, and the development of the school innovation practice has added bricks and mortar for the effective implementation of the teaching reform activities. The achievements of the teaching reform can enrich the connotation and form of the creative practice activities; the achievements of the creative practice activities are used to participate in the discipline competition, expand the project category of the competition, and in 
turn guide the inadequacy of the innovation activities; the three complement each other and promote each other, together to build a "Trinity" talent training model. Its core is to improve students' innovative ability $\left[4^{]}\right.$, which is as shown in Fig. 1.

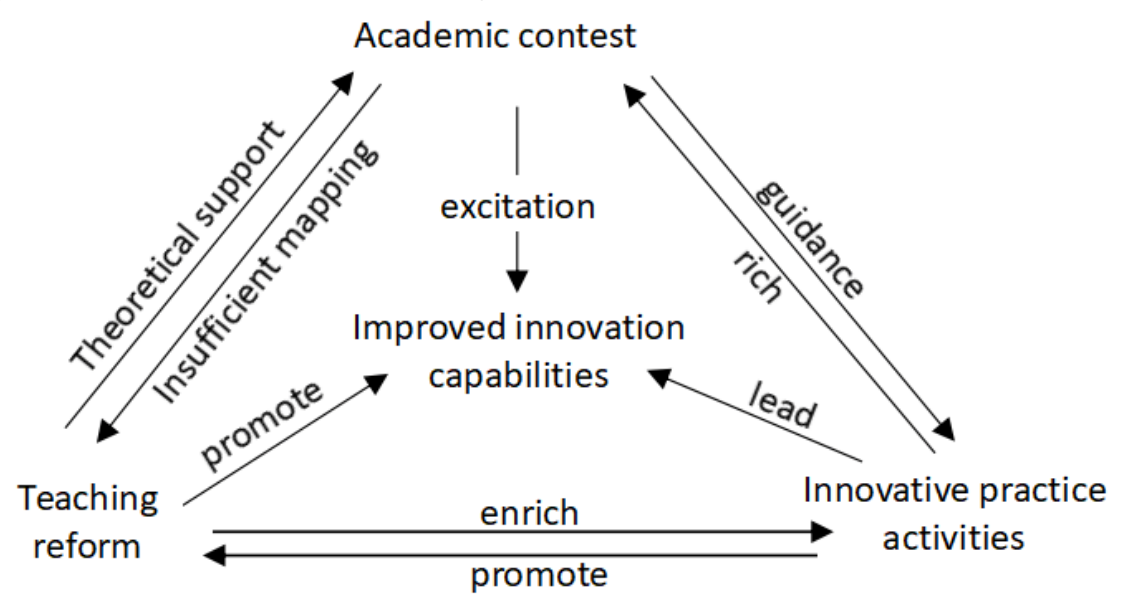

Figure 1. "Three in one" relationship diagram of training pattern

\section{Main influencing factors of "three in one" training mode in colleges and universities}

In order to fully understand the influence factors of the "Trinity" training model, I take a questionnaire survey to the university teachers, students and teaching managers of different age, different titles, different sex, different categories of students respectively to conduct a questionnaire survey, the effective questionnaire, such as table 1, table 2:

Table 1 Statistics of effective questionnaire for teaching workers

\begin{tabular}{ccccc}
\hline Age & lecturer & Associate professor & professor & teaching managers \\
\hline $30-40$ & 15 & 12 & 2 & 5 \\
$40-50$ & 2 & 16 & 4 & 3 \\
$50-60$ & 1 & 10 & 5 & 1 \\
\hline
\end{tabular}

Table 2 Statistics of effective questionnaire for students

\begin{tabular}{ccc}
\hline & \multicolumn{2}{c}{ Student Type } \\
Grade/gender & Student party members & Student league members \\
\hline Freshman[male] & 2 & 25 \\
Freshman[female] & 8 & 8 \\
Freshman[male] & 4 & 25 \\
Sophomore[male] & 15 & 8 \\
Junior[male] & 4 & 25 \\
Junior[female] & 15 & 8 \\
Senior (male) & 4 & 25 \\
Senior (female) & 2 & 8 \\
\hline
\end{tabular}


Factors affecting the training of three in one innovative practice talents

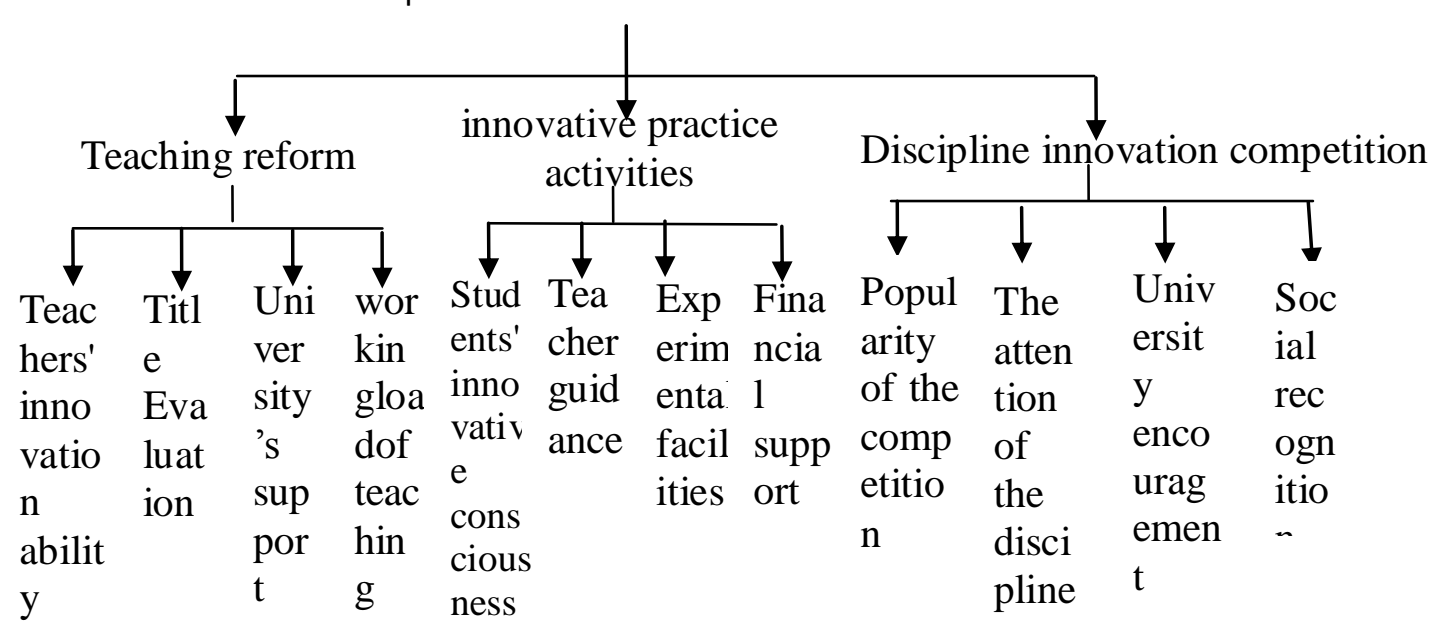

Figure 2. Important factors affecting the training mode of "three in one" innovative talents

To cultivate innovative talents, we want to achieve excellent achievements. We should start with three aspects: teachers' curriculum reform, students' innovative practice activities, and school encouragement to participate in the discipline competition. Establish a "three in one" training mode, analyze the factors affecting the "three in one", and advocate the reform and improvement of the important factors. The main influencing factors of the "three in one" training mode are: Students' innovative consciousness, teaching reform of theoretical courses, teachers' energy input and discipline importance.

\section{Measures to Improve the Training Mode of "Three in One" Training for Innovative Talents}

Strengthening the innovation consciousness of college students in the process of learning. To enhance college students' innovative consciousness, teachers should first stimulate students' desire for innovation and help students establish good creative thinking. However, at present, in the assessment mechanism of colleges and universities, the number of the educated is often taken as the standard to measure the quality of education, and the students' innovative thinking and innovation ability are imprisoned[3]. At present, the examination system of most colleges and universities has the scarcity of subjective evaluation and creativity, and the objective problem is many, which is not conducive to the students' understanding of the knowledge, the students' thinking is not active, so that the students' understanding and memory are not creative, the creativity of the students can not be cultivated and even stifled.Good innovation ability can not be separated from solid theoretical knowledge. For this reason, we should advocate the students to abandon the traditional concept of "to cope with the examination", to master the relevant theoretical knowledge, to attach importance to the cross connection between the various disciplines and to form a complete system of knowledge structure, laying a solid foundation for the future of society.

To stimulate the creative desire of college students, we should start with the freshmen, and need teachers and students to work together. For teachers, we should actively guide, promote the importance of innovation, encourage, support and guide the participation of all kinds of innovative activities.For students, it is necessary to eliminate psychological inferiority and build confidence. We should feel that they are possible. They should not think that only genius can be innovating. College students should have the spirit of indomitable, non inferiority and abandonment, and put their ideas into practice and innovate boldly.

Strengthening the Reform of Curriculum Teaching in Colleges and Universities. At present, few schools have brought the curriculum reform into the standard of professional title evaluation, so the university teachers will put more time in the related work of scientific research project, patent 
declaration, paper publication and so on. Teachers are not willing to spend too much time on the teaching mode of college curriculum. The direct way to change this situation is to increase the value of curriculum reform and its effect in the evaluation of professional titles.

The premise of the curriculum reform is that teachers should follow the quality oriented education concept of "people-oriented". The so-called "people-oriented" should be transformed from "instillation" teaching mode into teaching guided teaching mode and teaching students in accordance with their aptitude in the course of teaching[5].In order to cultivate innovative talents in teaching and research universities, it is imminent to change the traditional classroom teaching mode. From the point of teaching theoretical knowledge, teachers should give full play to the guiding role, give students the time to study independently, and give certain guidance from the way of inquiry, and then lead to the students' initiative in the direction of innovation, so that students not only learn knowledge, but also learn to use their knowledge. The channel for teachers to impart knowledge should be transformed from "single" to "pluralism", that is, knowledge is not only derived from textbooks, but also from life, network and society, and the innovation ability of "learning from doing" is truly mastered.

Encourage Teachers to Actively Invest in Students' Innovative Activities. In guiding discipline skills competition and college students' innovative practice, teachers need to spend a lot of time. Because of the heavy task of teachers' undergraduate teaching, it is necessary to squeeze out time to take part in the guidance of subject skills competition and innovative practice projects. Furthermore, although students are the main part of subject competition and college students' innovative practice activities, whether it is the program design of the competition or the topic selection and experiment of the college students' creative practice activities design, examination and acceptance can not be separated from teachers' guidance, which will take up a lot of time and energy from teachers. We should attach importance to both material and spiritual rewards, and take relevant incentive measures to achieve a benign sustainable development principle. Colleges and universities should attach importance to teachers' guiding students' practical work, so that teachers can make the work of guiding students' practical activities and scientific research projects, patent declarations, papers and other work.

As a teacher of higher education, we must have innovative thinking and the ability to master the latest achievements of our discipline[3].No matter when, university teachers should have strong sense of responsibility and innovative thinking while they have strong scientific research ability either.

The discipline gives full recognition and support to various innovative activities. In various evaluation indicators, it reflects the proportion of college students' innovation ability, or constructs corresponding evaluation system of innovation ability, and establishes a reasonable reward mechanism. Students who participate in all kinds of competitions are given awards for elective elective courses, elective courses and school elective courses according to the organizers and award-winning grades of the events, or in the required credits, which are also reflected in comprehensive survey and evaluation and evaluation awards. Through these measures, students are encouraged to cultivate their own sense of innovation and improve their innovative ability. Schools or disciplines can organize large-scale scientific and technological innovation competitions on a regular basis, build a positive atmosphere for academic innovation, and increase their efforts in funding, experimental sites, facilities, and so on. The cultivation of College Students' innovation ability is inseparable with the society, and the future is to serve the society. Therefore, the school should adhere to and perfect the school enterprise cooperation mode and build up a platform for training, training and improving the students' innovative practical ability.

\section{Acknowledgements}

Educational science research project of Qiqihar University, youth important items (2017092)

Qiqihar Science and Technology Bureau Project, Industrial issues (GYGG-201616) 


\section{Reference}

[1] F.Lv and J.M. Zhou: Journal of National Academy of Education Administration,(2017)No.3,p.3-8.In Chinese.

[2] Y.X. Zhao and Z. Y. Lv: Journal of North China University of Science and Technology(Social Science Edition), Vol.17(2017),No.2,p.92-96.In Chinese.

[3] Z.H. Liu: New West,(2009)No.12,p.161-162.In Chinese.

[4] X.Y. Huang: Adult Education,(2013)No.2,p.35-36.In Chinese.

[5] A.J. Huang: Course Education Research,(2017)No.24,p.5-6.In Chinese. 